\title{
Shadowing and Mobility Effect on Proactive and Reactive Routing Protocol in MANET
}

\section{ISTIKMAL ${ }^{1}$, SUGONDO HADIYOSO ${ }^{2}$, INDRARINI DYAH IRAWATI ${ }^{2}$ ARIF INDRA IRAWAN ${ }^{1}$}

\author{
${ }^{1}$ Fakultas Teknik Elektro, Universitas Telkom, Bandung \\ ${ }^{2}$ Fakultas Ilmu Terapan, Universitas Telkom, Bandung \\ Email: istikmal@telkomuniversity.ac.id
}

Received 8 Agustus 2021 | Revised 1 September 2021 | Accepted 14 September 2021

\begin{abstract}
ABSTRAK
Pada makalah ini, kami membandingkan protokol routing proaktif Optimized Link State Routing (OLSR) dan protokol routing reaktif Ad-hoc on-demand distance vector (AODV) dan Dynamic Source Routing (DSR) pada model propagasi Shadowing dan pergerakan pada mobile adhoc network (MANET). Terdapat dua skenario pengujian, yaitu dampak dari kecepatan pergerakan pengguna dan variasi waktu jeda pengguna dengan mobilitas Random Way Point (RWP). Hasil simulasi menunjukkan bahwa semakin besar kecepatan maka kinerja throughput akan menurun, sedangkan delay dan Normalized Routing Load (NRL) akan meningkat. Semakin lama waktu jeda, semakin lama topologi berubah, akibatnya parameter throughput meningkat sedangkan delay end-to-end dan NRL menurun. OLSR proaktif menunjukkan kinerja terbaik dibandingkan dengan protokol lain berdasarkan parameter throughput, sedangkan AODV reaktif mengungguli penundaan end-to-end dan parameter NRL.
\end{abstract}

Kata kunci: Protokol perutean, shadowing, Mobility, MANET

\section{ABSTRACT}

In this paper, we compared the proactive routing protocols Optimized Link State Routing (OLSR) and the reactive routing protocols Ad-hoc on-demand distance vector (AODV) and Dynamic Source Routing (DSR) in shadowing propagation and mobility model on mobile adhoc network (MANET). There are two test scenarios, such as the impact of user movement velocity and variations in user pause time with Random Way Point (RWP) mobility. In user velocity testing, the greater the speed, the throughput performance will decrease, while the delay and Normalized Routing Load (NRL) will increase. The pause time test describes the dynamics of changing network topology. The longer the pause time, the longer the topology changes, as a result, the throughput parameter increases while the end-to-end delay and NRL decrease. The proactive OLSR shows the best performance compared to other protocols based on throughput parameters, while the reactive AODV outperforms for end-to-end delay and NRL parameters.

Keywords: routing protocol, shadowing, Mobility, MANET 


\section{INTRODUCTION}

The routing protocol on the mobile Ad Hoc network responsibly to establish the communication path between the sender and the receiver. User movement and obstructions between the sender and receiver can cause the connection to deteriorate. The obstructions can cause a shadow effect. The shadow effect is explained as the effect of fluctuations in the received signal power due to the presence of a obstructions between the receiver and the transmitter user or devices. The shadowing barriers catch up and prevent the sent signal, causing relatively sluggish signal changes in compared to path loss model's nominal values. Changes in connection quality degradation due to shadowing effects will increase the probability of packet errors and connection drops. With the communication line disconnected, the routing protocol must re-find the path.

In a real-world urban setting, researchers studied the impact of propagation model on routing algorithm performance on Ad Hoc network (Angeles et al., 2016)(Gutiérrez et al., 2016)(Istikmal et al., 2019)(Kuwahara et al., 2021). These studies are using end-toend delay and delivery of packet rate to assess the routing performance. The impact of velocity speed to the protocol routing performance under the two way and the Nakagami-m of propagation loss model was investigated by (Aji Pratama et al., 2020), also modeled and analyzed of the shadow fading (Zhang et al., 2019). Using CORNER propagation model, the authors in (Guo et al., 2013)(Mukunthan et al., 2017), show the importance of the effect propagation model in network design using routing protocols. Moreover, the author in (Bakhtin et al., 2019), offers a way for implementing 3D obstacles, and their impact on signal propagation and one of the routing protocols for mobile Ad Hoc networks was tested. In (Huang et al., 2018), the authors elaborate a graph theory-based optimization approach for reducing the influence of the obstructive effect on the propagation of safety-related information.

In wireless network planning, the shadowing characterization data are commonly utilized to make adjustments to the link budget path loss calculations to account for statistical coverage estimations. Multiple reflections can generate somewhat slow change in Line-of-sight (LOS) components for some channels, causing an effect similar to blockage (Goldsmith, 2005; Liu et al., 2016). In Mobile Ad Hoc Networks, the author in (Amjad et al., 2015) study emphasizes the relevance of network performance and the physical layer using two-ray ground and shadowing propagation model. However, previous research did not analyze the impact of user's mobility based on pause time and velocity with reference shadowing distance on routing protocol performance.

Therefore, in this paper, we analyze the impact of user variation pause time and the mobility with random way point (RWP) in shadowing propagation model. The pause time in a mobility model is the time it takes for the user to return to the new destination after arriving at the first one. The shorter the pause period, the more dynamic the user's movements are. As a result, network topology changes more frequently. The user pause time movement and shadowing will have great impact on routing protocol performance.

\section{RESEARCH METHOD}

In this section, we investigates the correlation between shadowing and user movement mobility based on pause time and random way point to the routing protocol performance. In this research, we used proactive and reactive routing protocol. The Optimized Link State Routing (OLSR) known as proactive routing protocols, while Dynamic Source Routing (DSR) 
and Ad-hoc on-demand distance vector (AODV) known as reactive routing protocols (Nayyar, 2018). We compare the performance of these routing protocols in mobility scenario under shadowing propagation model. The separation distance between the transmitter and the receiver is commonly used to determine the received power attenuation. The power of received signal according to the time of measurement based on geographic location can be expressed as follows ( Liu et al., 2016):

$$
P_{r x}=\frac{1}{W} \sum_{n=i W}^{(i+1) W-1} \sum_{l=0}^{L-1}\left|h\left(n t_{r e p}, l \Delta \tau\right)\right|^{2},
$$

Simple empirical path loss modeling in decibels can be used to predict power attenuation after acquiring the received power versus the separation distance between the transmitter and the receiver, can be calculated as (Liu et al., 2016):

$$
P L(d)=A+10 \cdot n \cdot \log 10(d)+X_{\sigma} .
$$

According to (Goldsmith, 2005; Amjad et al., 2015), the authors combine path loss in the shadowing propagation model. Path loss is modeled simply and then combined with log-normal shadowing. This combined model produces power between transmitter-receiver which is expressed in $\mathrm{dB}$ as follows (Amjad et al., 2015):

$$
\frac{P_{r}}{P_{t}} d B=10 \log k-10 \cdot \gamma \cdot \log \frac{d}{d_{0}}-\varphi_{d B} .
$$

where $\gamma$ and $d_{0}$ are path loss exponent and reference distance, respectively. Gaussian distribution random variable and a unitless are $\varphi_{d B}$ and $k$. Moreover, to simplify in network simulator environment, there are two aspects to the shadowing model. The path loss model, which also estimates the mean received power at distance $d$, represented by $P_{r}(d)$. As a reference, it employs a close-in distance of $d . P_{r}(d)$ is calculated as follows in relation to $P_{r}\left(d_{0}\right)$.

$$
\frac{P_{r}\left(d_{0}\right)}{P_{t}(d)}=\left(\frac{d}{d_{0}}\right)^{\beta}
$$

The path loss exponent, $\beta$, is normally established empirically by field measurement. As distance increases, greater numbers equate to more obstructions, resulting in a faster fall in average received power. Table 1 shows the value of path loss exponent $\beta$ in typical environments and shadowing deviation $\sigma_{d B}$, refer to (Srinivasa and Haenggi, 2009).

Table 1. Path loss exponent and shadowing deviation

\begin{tabular}{llll}
\hline \multirow{2}{*}{ Typical } & \multicolumn{3}{c}{ Environments } \\
\cline { 2 - 4 } & \multicolumn{1}{c}{ Place } & $\boldsymbol{\beta}$ & $\boldsymbol{\sigma}_{\boldsymbol{d B}} \boldsymbol{*}$ \\
\hline Outdoor & Free Space area, LOS & 2.0 & 4 until 12 \\
\hline & Shadowed in urban place & 2.75 until 5.0 \\
\hline Indoor & In building, LOS & 1.6 until 1.8 \\
\hline & Obstructed indoor & 4.0 until 6.0 \\
\hline & Office with hard partition & & 7.0 \\
\hline & Office with soft partition & 9.6 \\
\hline
\end{tabular}


Finally, the shadowing model's second part reflects the change in received power at a given distance. It has a Gaussian distribution when measured in decibels since it is a log-normal random variable. The shadowing model as a whole is represented by

$$
\left[\frac{P_{r}(d)}{P_{t}\left(d_{0}\right)}\right]_{d B}=-10 \beta \log \left(\frac{d}{d_{0}}\right)+X_{d B}
$$

where $\sigma_{d B}$ is a standard deviation and $X_{d B}$ is a Gaussian random variable with a zero mean. The shadowing deviation, commonly known as $\sigma_{d B}$, is determined by measurement. Based on this shadowing propagation model, we investigated the performance of AODV, DSDV, and OLSR routing protocol in velocity and pause time scenarios. In this investigation, there are 30 nodes, where one sender will send data to one recipient through 28 other nodes which move randomly. Table 2 shows the simulation parameter in the network simulator.

Table 2. Simulation parameters

\begin{tabular}{lc}
\hline Mobility & Random Way Point \\
\hline Number of Nodes & 30 \\
\hline Packet Size & 1024 Bytes \\
\hline Sender/receiver node & 1 \\
\hline Velocity of nodes (m/s) & $2,4,6,8,10$ \\
\hline Propagation Model & Shadowing \\
\hline Routing Protocols & AODV, DSR, and OLSR \\
\hline Reference Distance & $1 \mathrm{~m}, 50 \mathrm{~m}$ \\
\hline Pause Time (second) & $0,10,20,30,40,50$ \\
\hline Power Transmits Tx & $0,28183815 \mathrm{~W}$ \\
\hline Frequency & $914 . \mathrm{e} 6 \mathrm{~Hz}$ \\
\hline High of the node (ht,hr) & $1,5 \mathrm{~m}$ \\
\hline
\end{tabular}

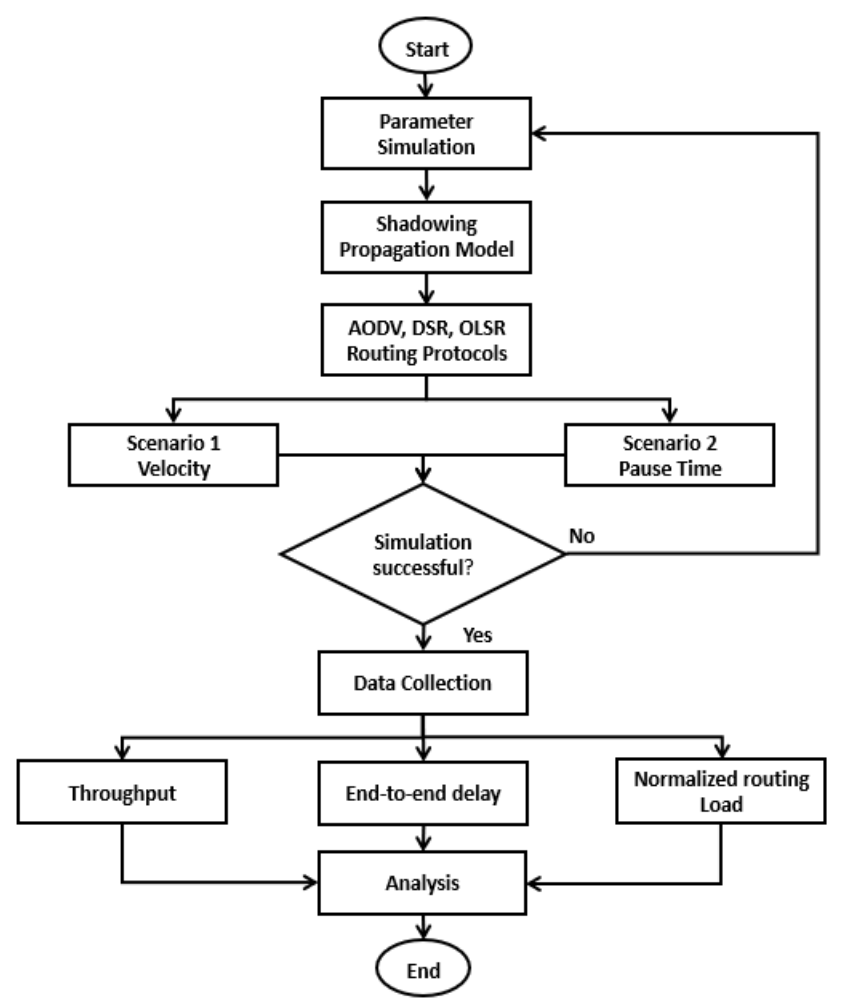

Figure 1. Research Method and simulation scenario 
Figure 1 show the research method and simulation scenario. We use throughput and end-toend delays parameter to measure the network performanceand normalized routing load (NRL) to see the routing protocol efficiency. The queuing, route discovery, latency, and buffering delays are assessed in milliseconds and included in the end-to-end delay performance analysis. We can calculate the throughput $B$, NRL by (Amjad et al., 2015):

$$
\begin{gathered}
B=\frac{\text { data packets success fully delivered }}{\text { observation time }} \\
N R L=\frac{\text { The total number of routing packets generated }}{\text { the number of data packets successfully delivered to destination }}
\end{gathered}
$$

In this simulation, the mobility of nodes using random way point, where the node freely to move to any direction. In the first scenario, we want to investigate the routing protocol performance against the shadowing and the increase of the node velocity. The impact of the pause time in dynamically change of topology and at the same time the node has shadowing effect on routing protocol performance is the purpose of the second scenario. The nodes choose a random destination anywhere in the network and begin moving towards it at a constant speed in this mobility model. After arriving at the destination, the node will wait for the amount of time indicated by the "pause time" argument. Once the pause time has passed, the node will restart moving in a new direction until the simulation is completed.

\section{RESULTS AND DISCUSSION}

In reactive routing protocol, when the source wants to transmit the data, if there is no valid route, the route request (RREQ) will be broadcast by the source to the all neighbors. When the RREQ is received at the destination node, it is replayed as a route reply (RREP) and forwarded to the source node over a unicast link. The source node begins transmitting the data after receiving RREP. Meanwhile, proactive routing protocol will maintain the valid path periodically, even though the source is not sending data.

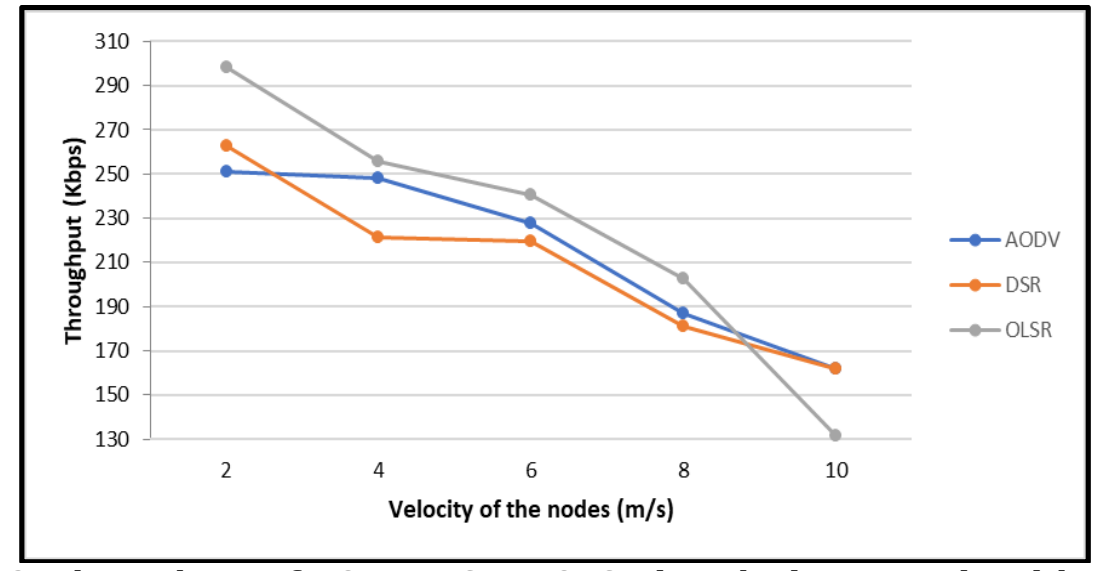

Figure 2. Throughput of AODV, DSDV, OLSR in velocity scenario with $d=1 \mathrm{~m}$ 


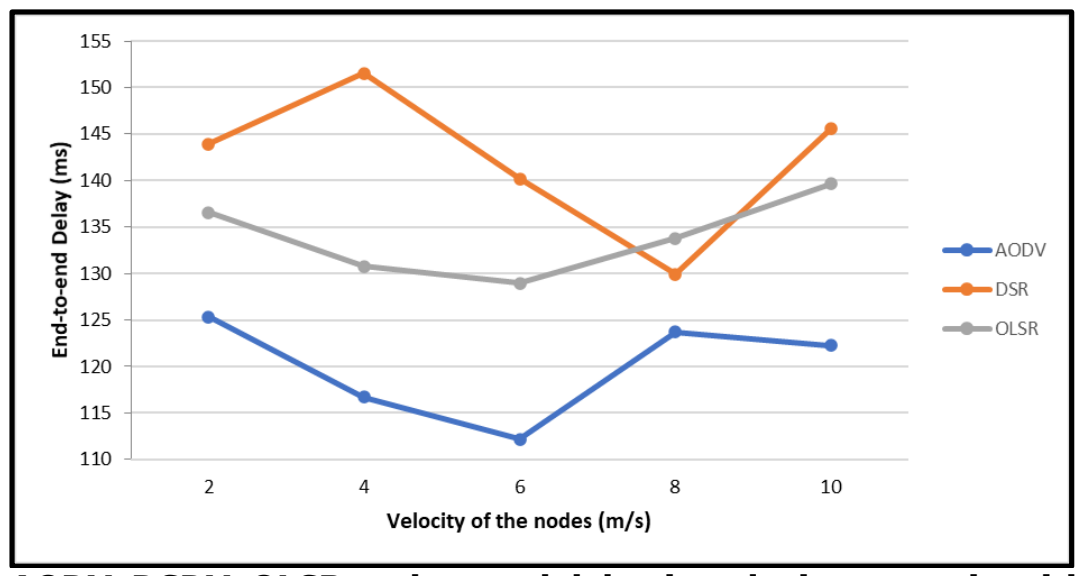

Figure 3. AODV, DSDV, OLSR end-to-end delay in velocity scenario with $d=1 \mathrm{~m}$

Figure 2 dan 3 shows the throughput and end-to-end delay performance of AODV, DSR, and OLSR routing protocol in velocity scenario with reference distance in shadowing $1 \mathrm{~m}$. The OLSR routing protocol outperforms in average throughput than AODV and DSR. However, AODV gain advantages with smallest end-to-end delay. The OLSR used the concept of multi-point relay (MPR) to improve network performance, while in AODV, it can reduce the rate of increase in end-to-end delay, but does not obtain optimal throughput.

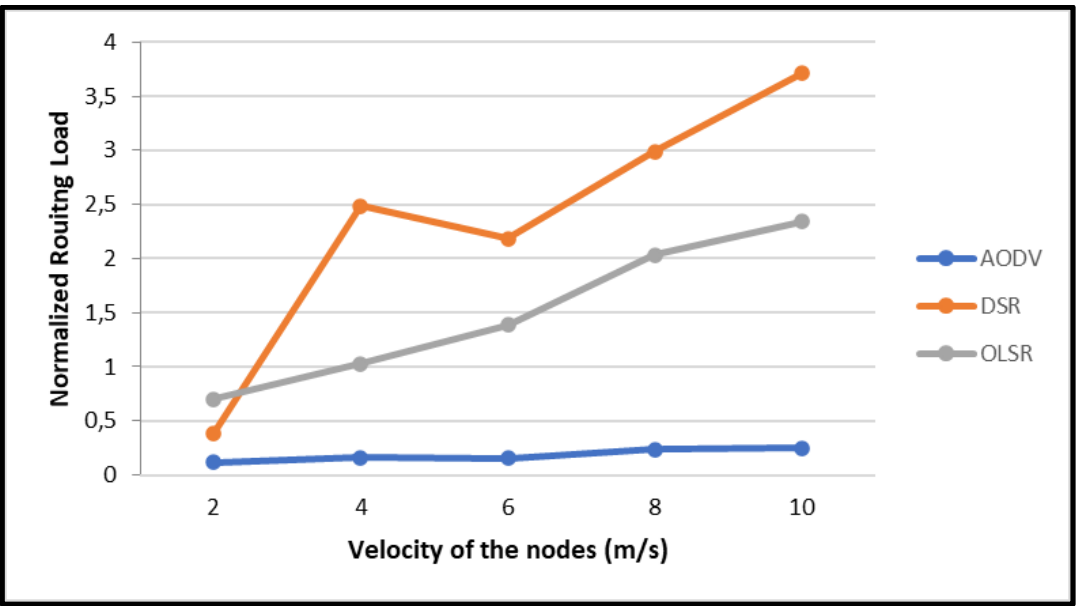

Figure 4. The AODV, DSDV, OLSR NRL in velocity scenario with $d=1 \mathrm{~m}$

Figure 4 shows the difference in efficiency between reactive and proactive routing protocols based on NRL values. Although, OLSR and DSR get better performance in throughput and endto-end, they produce higher NRL values than AODV. The smaller the NRL value, the more efficient the routing protocol algorithm. The velocity and shadowing lead the routing protocol to face signal quality connection degradation, this is also reporting in (Istikmal et al., 2015), path break and higher bit error rate. Increasing the node velocity will decrease average throughput and increase NRL and average end-to-end delay. The throughput and end-to-end delay AODV, DSR, and OLSR routing protocol performance in pause time scenario with reference distance in shadowing $50 \mathrm{~m}$ is shown in Figure 5 and 6, respectively. 


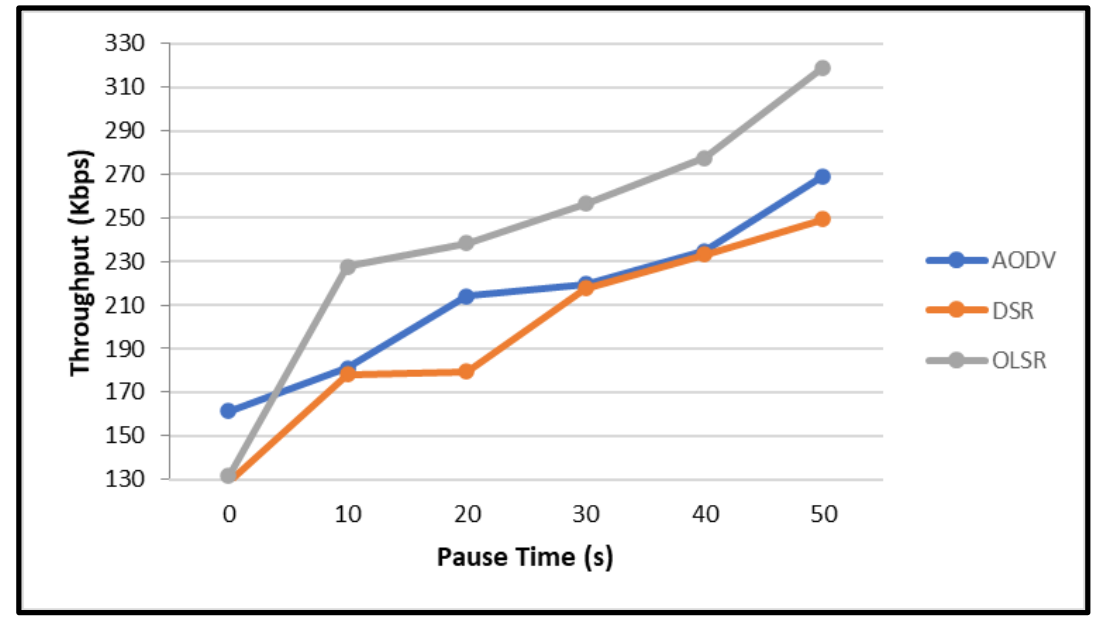

Figure 5. Throughput of AODV, DSDV, OLSR in pause time scenario with $d=50 \mathrm{~m}$

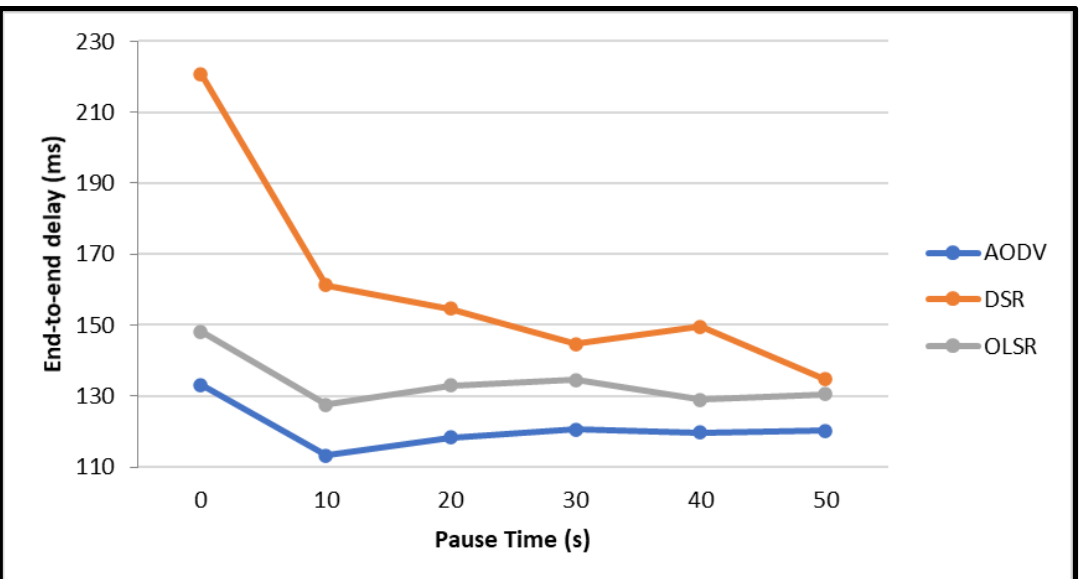

Figure 6. The AODV, DSDV, OLSR end-to-end delay in pause time scenario with $d=50 \mathrm{~m}$

The shorter the pause time duration, the more dynamically the network topology will change. These will lead path break and makes routing protocol enter the route discovery process. At the same time, the shadowing influences the degradation of the signal quality connection. This will lead path break and makes routing protocol frequently enter the route discovery process. Fig. 7 shows the normalized routing load of AODV, DSDV, OLSR in pause time scenario with $d=50 \mathrm{~m}$.

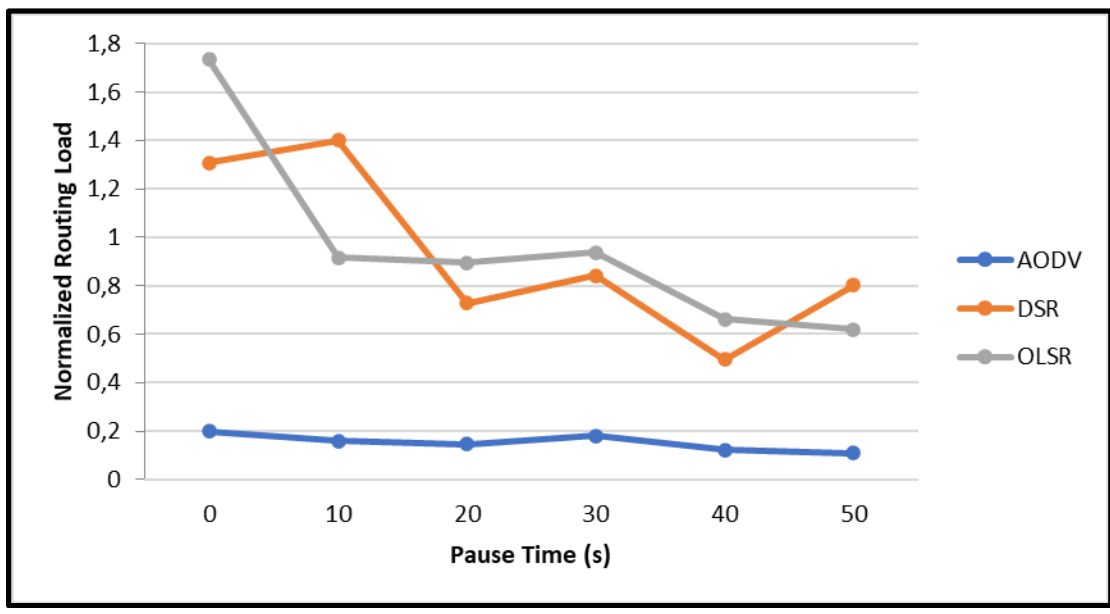

Figure 7. The normalized routing load of AODV, DSDV, OLSR in pause time scenario with $d$ $=50 \mathrm{~m}$ 
The simulation result shows that AODV outperform than DSR and OLSR in term of NRL performance. As a reactive routing protocol, the AODV generates routing packets when forming a new topology. This is the reason that AODV has the lowest NRL. The number of routing packets is much less than the number of data packets received at the destination. Based on these results, a new method of routing protocols is needed to be able to adapt to the shadowing environment, among others are the probability-based reliable routing (Sun et al., 2019)(Xu et al., 2020) and cross layer scheme (Istikmal et al., 2017)(Wu et al., 2021) between physical layer and routing protocol. The modification of these methods in routing protocol algorithm, can be considered to improve network performance.

\section{CONCLUSION}

We have successfully simulated Ad Hoc network topology and tested the performance of AODV, DSR, and OLSR routing protocols based on shadow propagation models. Routing protocol performance is measured by parameters of throughput, end to end delay, and NRL with random user movements. The speed change simulation shows that the higher the speed, the lower the throughput, the higher the end-to-end delay and the NRL. Based on experiments, users with a speed of $6 \mathrm{~m} / \mathrm{s}$ showed the best performance on the three routing protocols. In the scenario of topology changes that are simulated with changes in pause time, it shows that the longer the pause time, the higher the throughput and the lower end-to-end delay and NRL. The proactive OLSR has superior performance based on throughput parameters because this protocol is always adaptive to update the routing table and has multi-point relay strategy. However, OLSR has a large NRL due to the large number of routing packets sent for this purpose and results in long delays. The reactive protocol AODV has superior performance in end-to-end delay and NRL. Cross layer scheme and probability-based reliable routing can be considered as methods to improve routing protocol performance for future research.

\section{ACKNOWLEDGEMENT}

This work is supported by Telkom University and Telkom Foundation

\section{REFERENCES}

Aji Pratama, R., Rosselina, L., Sulistyowati, D., Fitri Sari, R., and Harwahyu, R. (2020). Performance Evaluation on VANET Routing Protocols in the Way Road of Central Jakarta using NS-3 and SUMO. Proceedings 2020 International Seminar on Application for Technology of Information and Communication: IT Challenges for Sustainability, Scalability, and Security in the Age of Digital Disruption (iSemantic 2020), (pp. 280285). https://doi.org/10.1109/iSemantic50169.2020.9234202

Amjad, K., Ali, M., Jabbar, S., Hussain, M., Rho, S., and Kim, M. (2015). Impact of dynamic path loss models in an urban obstacle aware ad hoc network environment. Journal of Sensors, 2015, (pp. 1-9). https://doi.org/10.1155/2015/286270

Angeles, W., Borin, V. P., Munaretto, A., and Fonseca, M. (2016). The impact of propagation models in the performance of ad hoc routing protocols for urban VANET. IEEE Vehicular 
Technology Conference, (pp. 1-5). https://doi.org/10.1109/VTCFall.2016.7881251

Bakhtin, A., Gorelik, A., Volkov, A., Konoplev, A., and Muratchaev, S. (2019). Development of obstacles that influence signal propagation in NS3. 11th IEEE International Conference on Application of Information and Communication Technologies, AICT 2017, (pp. 1-3). https://doi.org/10.1109/ICAICT.2017.8686869

Goldsmith, A. (2005). Wireless Communications, Cambridge University Press, UK.

Guo, Y., Stolyar, A. L., and Walid, A. (2013). Shadow-Routing Based Dynamic Algorithms for Virtual Machine Placement in a Network Cloud. 2013 Proceedings IEEE INFOCOM, (pp. 620-628). https://doi.org/10.1109/TCC.2015.2464795

Gutiérrez, E. S., Herrera, A. C., and Prado, G. R. (2016). XBee distance measurement through the log normal shadowing model. 2016 IEEE International Autumn Meeting on Power, Electronics and Computing (ROPEC 2016), (pp. 1-5). https://doi.org/10.1109/ROPEC.2016.7830624

Huang, R., Wu, J., Long, C., Zhu, Y., Li, B., and Lin, Y. B. (2018). Mitigate the obstructing effect of vehicles on the propagation of VANETs safety-related information. IEEE Transactions on Vehicular Technology, 677), 5558-5569. https://doi.org/10.1109/TVT.2018.2802905

Istikmal, Kurniawan, A., and Hendrawan. (2015). Throughput Performance of Routing Protocols Based on SNR in Wireless Mobile Ad Hoc Networks. 2015 1st International Conference on Wireless and Telematics (ICWT), (pp. 1-6). https://doi.org/10.1109/ICWT.2015.7449226

Istikmal, Kurniawan, A., and Hendrawan. (2017). Selective Route Based on SNR with CrossLayer Scheme in Wireless Ad Hoc Network. Journal of Computer Networks and Communications, 2017, (pp. 1-14). https://doi.org/10.1155/2017/1378374

Istikmal, Subekti, A., Perdana, D., Ridha Muldina, N., Arifindra, I., and Sussi. (2019). Dynamic source routing and optimized link state routing performance in multipath fading environment with dynamic network topology. 2019 4th International Conference on Information Technology, Information Systems and Electrical Engineering (ICITISEE 2019), (pp. 373-378). https://doi.org/10.1109/ICITISEE48480.2019.9003887

Kuwahara, Y., Aihara, N., Yamazaki, S., Ohuchi, K., and Mizuno, H. (2021). Energy-Efficiency Comparison of Ad-hoc Routings in a Shadowing Environment for Smart IoT. International Conference on Information Networking, (pp. 801-804). https://doi.org/10.1109/ICOIN50884.2021.9333990

Liu, L., Tao, C., Matolak, D. W., Zhou, T., and Chen, H. (2016). Investigation of Shadowing 
Effects in Typical Propagation Scenarios for High-Speed Railway at $2350 \mathrm{MHz}$. International Journal of Antennas and Propagation, 2016, 1-9. https://doi.org/10.1155/2016/8782671

Mukunthan, A., Cooper, C., Safaei, F., Franklin, D., and Abolhasan, M. (2017). Leveraging the Propagation Model to Make Greedy Routing Decisions in Urban Environments. IEEE Vehicular Technology Conference, 2017-June, (pp. 1-6). https://doi.org/10.1109/VTCSpring.2017.8108451

Nayyar, A. (2018). Flying Ad Hoc Network (FANETs): Simulation Based Performance Comparison of Routing Protocols: AODV, DSDV, DSR, OLSR, AOMDV and HWMP. 2018 International Conference on Advances in Big Data, Computing and Data Communication Systems, iCABCD 2018, (pp. 1-9). https://doi.org/10.1109/ICABCD.2018.8465130

Srinivasa, S., and Haenggi, M. (2009). Path loss exponent estimation in large wireless networks. Information Theory and Applications Workshop ITA 2009, (pp. 124-129). https://doi.org/10.1109/ITA.2009.5044933

Sun, G., Song, L., Yu, H., Chang, V., Du, X., and Guizani, M. (2019), V2V routing in a VANET based on the autoregressive integrated moving average model. IEEE Transactions on Vehicular Technology, 68(1), 908-922. https://doi.org/10.1109/TVT.2018.2884525

Wu, Y., Pickavet, M., and Colle, D. (2021). Performance Analysis of Optimization Algorithms for A Cross-Layer Shadowing Recover Scheme. IEEE Transactions on Network and Service Management. https://doi.org/10.1109/TNSM.2021.3053145

Xu, C., Xiong, Z., Kong, X., Zhao, G., and Yu, S. (2020). A Packet Reception Probability-Based Reliable Routing Protocol for 3D VANET. IEEE Wireless Communications Letters, 9(4), 495-498. https://doi.org/10.1109/LWC.2019.2960236

Zhang, K., Li, B., Tang, X., Wang, D., and Wei, L. (2019). Path loss measurement and modeling for industrial environment. IEEE International Conference on High Performance Switching and Routing, 2019May, (pp. 1-5). https://doi.org/10.1109/HPSR.2019.8808124 